\title{
Prevalence and risk factors of falls among community-dwelling older people: results from three consecutive waves of the national health interview survey in Taiwan
}

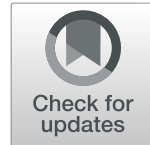

Yih-Jian Tsai ${ }^{1}$, Ping-Yen Yang ${ }^{1}$, Yi-Ching Yang ${ }^{2}$, Mau-Roung Lin $^{3}$ and Ying-Wei Wang ${ }^{1,4^{*}}$ (D)

\begin{abstract}
Background: An aging society incurs great losses due to fall-related injuries and mortalities. The foreseeable increased burden of fall-related injury among older people requires a regular nationwide study on the fall epidemic and prevention strategies.

Methods: The fall epidemic was examined using data from three consecutive waves of the National Health Interview Survey (2005, 2009, and 2013). Common explanatory variables across these surveys included sociodemographic factors (age, sex, and difficulty in performing activities of daily living (ADL) or instrumental ADL), biological factors (vision, comorbidities, urinary incontinence, and depressive symptoms), and behavioral risk factors (sleeping pill use, and frequency of exercise). After the univariate and bivariate analyses, the prevalence of falls was investigated using multiple linear regression models adjusted for age group, sex, and year of survey. A multivariate logistic regression model for falls with adjustments for these common explanatory variables was established across three waves of surveys. The effect of fall prevention programs was examined with the effect size in terms of agespecific and sex-specific prevalence of falls and fall-related hospitalization rates during 2005 and 2009.
\end{abstract}

Results: For each survey, there were consecutively 2722; 2900; and 3200 respondents with a mean age of 75.1, 75.6, and 76.4 years, respectively. The multiple linear regression model yielded a negative association between the prevalence of falls and year of survey. Several sociodemographic and biological factors, including female sex, difficulty in performing one basic ADL, difficulty in performing two or more instrumental ADLs, unclear vision, comorbidities, urinary incontinence, and depressive symptoms, were significantly associated with falls. In contrast to the universal positive effect on the prevalence of falls among older adults, the effect size of fall-related hospitalization rates revealed a $2 \%$ relative risk reduction only for those aged $65-74$ years, but deteriorated for those aged 75-84 (-10.9\%).

Conclusion: Although the decline in fall prevalence over time supports existing fall intervention strategies in Taiwan, the differential prevention effect and identification of risk factors in older people suggest the necessity of adjusting fall prevention programs.

Keywords: Prevalence, Risk factors, Fall prevention, Elderly

\footnotetext{
* Correspondence: ywwang@hpa.gov.tw

${ }^{1}$ Health Promotion Administration, Ministry of Health and Welfare, Taipei,

Taiwan

${ }^{4}$ Hualien Tzu Chi Hospital, Tzu Chi University and Hospital, Hualien, Taiwan

Full list of author information is available at the end of the article
}

C The Author(s). 2020 Open Access This article is licensed under a Creative Commons Attribution 4.0 International License, which permits use, sharing, adaptation, distribution and reproduction in any medium or format, as long as you give appropriate credit to the original author(s) and the source, provide a link to the Creative Commons licence, and indicate if changes were made. The images or other third party material in this article are included in the article's Creative Commons licence, unless indicated otherwise in a credit line to the material. If material is not included in the article's Creative Commons licence and your intended use is not permitted by statutory regulation or exceeds the permitted use, you will need to obtain permission directly from the copyright holder. To view a copy of this licence, visit http://creativecommons.org/licenses/by/4.0/ The Creative Commons Public Domain Dedication waiver (http://creativecommons.org/publicdomain/zero/1.0/) applies to the data made available in this article, unless otherwise stated in a credit line to the data. 


\section{Background}

The annual prevalence of falls has increased by age, from 28 to $35 \%$ for people aged $\geq 65$ years to 32 to $42 \%$ for those aged $>70$ years [1]. As the burden of fall-related injury increased annually by $21.1 \%$ between 1990 and 2013, falls among older people have become a global health concern. Furthermore, the burden of fall-related injuries reached a new peak of 27.5 million disabilityadjusted life years in 2013 [2]. Falls have not only created tremendous costs in high-income countries [3-6], but the increased rate of fall-related injuries has gradually affected the health and ability of older individuals in low- and middle-income countries to perform daily tasks. Main risk factors for falls are categorized into four dimensions: biological, behavioral, environmental, and socioeconomic factors [1]. Given the multifactorial etiology of falls [7], the prevalence and risk factors of falls or fall-related injuries vary by age of the target population, country, outcomes, and covariates measured, etc. For the need of setting up a sound evidence base of fall prevention policy, increasing number of countries include fall-related issues in national surveys.

Analysis of the 1997-2010 National Health Interview Survey (NHIS) in the United States revealed that $61.9 \%$ of all fall-related injuries among older women occurred indoors while occurred $32.8 \%$ outdoors. Sedentary older individuals usually experience fall-related injuries indoors, while older people with a high level of physical activity experience falls outdoors [8]. While the multivariable logistic regression (MLR) models showed that both sexes shared some risk factors for falls, such as chronic health conditions and severe pain, sex-specific risk factors were also identified. These risk factors include incontinence and frailty for women, and depressive symptoms, advanced age, and inability to maintain fulltandem stance for men [9].

In low- and middle-income countries, the pooled prevalence of past-year fall-related injuries was $4 \%$ across six countries (China, Ghana, India, Mexico, Russian Federation, and South Africa) [10]. However, among these countries and Indonesia, the most common risk factors of fall-related injuries in older adults is having two or more comorbidities, and the less common risk factors include depression, sleeping problems, and poor cognitive function $[10,11]$.

In southern Taiwan, falls accounted for $60 \%$ of trauma admissions of older patients in 2009 and 2013 [12]. Analysis of data from the 1996 and 1999 Taiwan Longitudinal Study on Aging demonstrated that the overall prevalence of falls was $19.5 \%$. Furthermore, the risk of falling was higher among individuals with the following characteristics: female sex, having a disability, reduced activities of daily living (ADL) function, depressive symptoms, using a cane or a walker but still walking well, and not wearing glasses but not seeing clearly [13]. In response to concerns about the growing health care burden from fall injury in companion with an ageing population, a multifactorial fall risk awareness program was launched in 2004 and later integrated into Health Promotion Programs for the Elderly in 2009 [14]. In this study, we attempt to investigate the prevalence and risk factors for falls among community-dwelling older people in 2005, 2009, and 2013, and the effect of fall prevention programs on selected fall-related outcomes, to better document fall prevention policies.

\section{Methods}

\section{Study subjects and data collection}

Data of persons aged $\geq 65$ years were collected from three consecutive waves of the NHIS (2005, 2009, and 2013) in Taiwan. The design and sampling strategies used for the 2005 NHIS were described in a previous report [15]. Those who could not tolerate an interview because of self-perceived physical weakness, difficult hearing, deafness, dumbness, or mental problems were replaced by proxy as stipulated, rather than being excluded from the study. Participants were drawn at a probability proportional to the size of the older population using a multiple-stage, stratified, systematic sampling design. In summary, we drew consecutively 187, 164, and 168 of the 358 townships or districts nationwide for each wave of surveys. These townships or districts drawn were further divided into 53 strata according to their geographic location, population distribution, and preceding interview experience. Within each stratum selected, sampling stages varied by the degree of urbanization. Two-stage sampling was conducted for those within high urbanization strata, first with neighborhood unit and then persons. Three-stage sampling was conducted for those within the moderate urbanization strata, first with villages, followed by neighborhood unit and persons, and for those within rural or remote strata, first with townships/districts, followed by neighborhood unit and persons. Between April 2005 and August 2005, data were collected from 2727 persons (85.5\%) among 3188 eligible subjects aged $\geq 65$ years using face-to-face questionnaire interviews for the NHIS. The 2009 and 2013 NHIS surveys were conducted in a similar manner to the 2005 NHIS survey using a Computer Assisted Personal Interview. These surveys had response rates of $88.2 \%$ (2904/3294) and $82.8 \%$ (3204/3868), respectively. After four or five respondents who did not specify their fall experience in each consecutive wave of survey in 2005, 2009, and 2013 were excluded, 2722; 2900; and 3200 respondents were included in the analysis. Data quality was assured through standardization of the questionnaire administration process and auditing. 


\section{Outcomes and explanatory variables}

A fall was defined as "an event of falling down that occurs while one stands up, sits down, gets into bed, or walks, etc., regardless of its underlying causes or resting on a same or lower level." Each participant that experienced a fall was required to answer (Yes/No) if he/she had experienced a fall, regardless of frequency, in the past year.

Common explanatory variables that were chosen for the correlation analyses with fall data included sociodemographic factors (age, sex, and difficulty in performing activities of daily living (ADL) or instrumental ADL), biological factors (vision, comorbidities, urinary incontinence, and depressive symptoms [16]), and behavioral risk factors (sleeping pill use, and frequency of exercise) (Additional file 1: Table S1).

\section{Statistical analyses}

The statistical software package used to conduct analyses was SAS version 9.3. For each wave of survey results, data were weighted to correct for the probability of multistage sampling. Univariate analyses were used to examine the frequency distribution of each explanatory variable. The chi-square test was used to compare the risk of falling across each explanatory variable. The prevalence of falls was defined according to the proportion of participants who experienced at least a fall in the population at risk in the past year and was further stratified by age group and sex to obtain stable estimates of age- and sex-specific prevalence. A multiple linear regression model that was adjusted for age group, sex, and year of the survey was used to examine the timedependent changes in the age- and sex-specific prevalence of falls. A MLR model was established and adjusted for all the aforementioned common explanatory variables to investigate the independent association between each explanatory variable and the odds of having experienced a fall in the past year. Statistical significance was set at $\alpha=0.05$. The time-dependent trends of age- and sex-specific prevalence of falls were then compared with those of the overall, sex-specific, and age-specific fall-related hospitalization rates between 2003 and 2009 [17]. The effect of fall prevention programs during 2005 and 2009 was examined with the effect size of relative risk reduction [18] in terms of age-specific and sex-specific prevalence of falls and fall-related hospitalization rates derived from a previous report [17]. For each specific rate, the effect size was defined as the rate difference during 2005 and 2009, divided by the observed rate in 2005, as calculated in the following.

$$
\text { Es }=100 *\left(r_{0}-r_{1}\right) / r_{0}
$$

Where, Es stands for the effect size (\%). Es $>0$ means a positive effect, while Es $<0$ means a negative effect. $r_{0}$ was the observed rate in 2005 , when the baseline measurement was taken. It was plausible because the multifactorial fall risk awareness program was just a pilot study in 2004 for a later distribution.

$\mathrm{r}_{1}$ was the observed rate in 2009, which was regarded as the effect measurement for comparison based on data availability.

\section{Results}

The characteristics of the participants varied across the three consecutive waves of national surveys in 2005 and 2013 (Table 1). Characteristics that increased by survey included the proportions for those aged $80-84$ years, aged $\geq 85$ years, and using sleeping pills (from 10.9, 12.6, to $14.9 \%)$. Accordingly, the mean age $( \pm \mathrm{SD})$ of respondents increased from $75.1 \pm 6.0,75.6 \pm 6.3$, to $76.4 \pm 6.5$ years, respectively. The proportion of two or more comorbidities also escalated from $31.2,32.5$, to $39.1 \%$. On the contrary, those characteristics that decreased by survey included the proportions for unclear vision (from 25.6, 24.9, to 20.3\%), irregular exercise (from 6.1, 5.0, to $3.5 \%$ ), and depressive symptoms (from 28.6, 23.6, to $20.4 \%)$.

Table 2 shows that the proportions of some morbidities increased in 2005 and 2013 for hypertension (from $43.1,49.1$, to $53.3 \%$ ), diabetes (from $17.8,19.3$, to $22.5 \%$ ), hyperlipidemia (from 23.3, 24.0, to $26.8 \%$ ), and asthma (from 5.2, 5.3, to 6.3\%), while the proportions of other morbidities fluctuated. With regard to the prevalence of falls, those older adults who had any of the selected chronic conditions tended to have a higher risk of falls than those who had none.

Table 3 reveals the risk of falls varied by each variable and survey. Risk of falls was higher in women and those with advanced age, with the exception of women in 2013 and those aged $\geq 85$ years between 2005 and 2009. Older people who had urinary incontinence and depressive symptoms and used sleeping pills tended to have a higher risk of falls. Moreover, older adults were more likely to have a fall with a higher number of comorbidities and of IADL difficulty, but not with that of ADL difficulty. Notably, there was a gradient of protective effect from risk of falls by vision quality, with a moderate risk for average vision and a higher risk for unclear vision. Older people who took regular exercise had their fall risk reduced by 26 to $43 \%$ in 2005 and 2013 .

As shown in Table 1, the weighted prevalence of falls (and 95\% confidence interval) over the previous year gradually dropped from $21.3 \%$ (95\% CI $19.6-23.1 \%$ ), $17.5 \%$ (95\% CI $15.7-19.2 \%$ ), to $16.5 \%$ (95\% CI $14.8-$ $18.3 \%$ ) across three waves of survey. With further adjustment for age, sex, and year of survey accounting for $76 \%$ of the total variation in the multiple linear regression model $\left(R^{2}=0.76\right.$ in Additional file 2: Table S2), the age- 
Table 1 Characteristics of study subjects by number of participants and prevalence of falls during survey years

\begin{tabular}{|c|c|c|c|c|c|c|c|c|c|c|c|c|}
\hline \multirow[t]{3}{*}{ Characteristics } & \multicolumn{4}{|l|}{2005} & \multicolumn{4}{|l|}{2009} & \multicolumn{4}{|l|}{2013} \\
\hline & \multicolumn{2}{|c|}{$\begin{array}{l}\text { No. of } \\
\text { participants }\end{array}$} & \multicolumn{2}{|c|}{$\begin{array}{l}\text { Prevalence of } \\
\text { falls and } p \text {-value }\end{array}$} & \multicolumn{2}{|c|}{$\begin{array}{l}\text { No. of } \\
\text { participants }\end{array}$} & \multicolumn{2}{|c|}{$\begin{array}{l}\text { Prevalence of } \\
\text { falls and } p \text {-value }\end{array}$} & \multicolumn{2}{|c|}{$\begin{array}{l}\text { No. of } \\
\text { participants }\end{array}$} & \multicolumn{2}{|c|}{$\begin{array}{l}\text { Prevalence of } \\
\text { falls and } p \text {-value }\end{array}$} \\
\hline & $N=2722$ & $\%$ & $\mathrm{n}$ & $\%$ & $N=2900$ & $\%$ & $\bar{n}$ & $\%$ & $N=3200$ & $\%$ & $\mathrm{n}$ & $\%$ \\
\hline Total & 2722 & 100.0 & 579 & 21.3 & 2900 & 100.0 & 565 & 17.5 & 3200 & 100.0 & 528 & 16.5 \\
\hline Mean age $( \pm S D$, year) & 75.1 & \pm 6.0 & & & 75.6 & \pm 6.3 & & & 76.4 & \pm 6.5 & & \\
\hline Age & & & & 0.002 & & & & 0.017 & & & & 0.004 \\
\hline $65-69$ & 868 & 31.9 & 147 & 16.9 & 877 & 30.2 & 131 & 14.0 & 852 & 26.6 & 110 & 12.1 \\
\hline $70-74$ & 743 & 27.3 & 161 & 20.9 & 726 & 25.0 & 141 & 18.5 & 866 & 27.1 & 135 & 16.2 \\
\hline $75-79$ & 619 & 22.7 & 141 & 23.2 & 653 & 22.5 & 131 & 16.4 & 654 & 20.4 & 115 & 17.9 \\
\hline $80-84$ & 329 & 12.1 & 88 & 28.1 & 388 & 13.4 & 96 & 23.0 & 503 & 15.7 & 99 & 18.7 \\
\hline $85+$ & 163 & 6.0 & 42 & 26.1 & 256 & 8.8 & 66 & 21.3 & 325 & 10.2 & 69 & 24.3 \\
\hline Sex & & & & $<0.001$ & & & & $<0.001$ & & & & 0.224 \\
\hline Male & 1346 & 49.4 & 221 & 16.5 & 1252 & 43.2 & 198 & 14.1 & 1523 & 47.6 & 227 & 15.3 \\
\hline Female & 1376 & 50.6 & 358 & 26.2 & 1648 & 56.8 & 367 & 20.6 & 1677 & 52.4 & 301 & 17.5 \\
\hline ADL difficulty & & & & $<0.001$ & & & & $<0.001$ & & & & $<0.001$ \\
\hline None & 2324 & 85.4 & 419 & 18.1 & 2382 & 82.2 & 399 & 15.2 & 2658 & 83.1 & 379 & 13.8 \\
\hline 1 task & 74 & 2.7 & 33 & 45.9 & 109 & 3.8 & 33 & 29.0 & 112 & 3.5 & 38 & 44.5 \\
\hline$\geq 2$ tasks & 322 & 11.8 & 127 & 39.4 & 406 & 14.0 & 133 & 28.4 & 427 & 13.4 & 111 & 27.2 \\
\hline IADL difficulty & & & & $<0.001$ & & & & $<0.001$ & & & & $<0.001$ \\
\hline None & 1574 & 58.1 & 232 & 15.0 & 2275 & 79.4 & 371 & 14.8 & 1943 & 61.5 & 244 & 11.9 \\
\hline 1 task & 361 & 13.3 & 67 & 19.0 & 105 & 3.7 & 28 & 25.1 & 349 & 11.0 & 57 & 16.0 \\
\hline$\geq 2$ tasks & 775 & 28.6 & 278 & 35.7 & 486 & 17.0 & 161 & 29.1 & 868 & 27.5 & 216 & 27.5 \\
\hline Use of sleeping pills use & & & & 0.005 & & & & 0.022 & & & & 0.009 \\
\hline No & 2422 & 89.1 & 496 & 20.4 & 2521 & 87.4 & 468 & 16.7 & 2715 & 85.1 & 422 & 15.4 \\
\hline Yes & 297 & 10.9 & 83 & 28.6 & 363 & 12.6 & 94 & 22.9 & 477 & 14.9 & 106 & 22.3 \\
\hline Vision & & & & $<0.001$ & & & & 0.002 & & & & $<0.001$ \\
\hline Clear & 772 & 32.1 & 129 & 17.4 & 815 & 32.0 & 109 & 12.8 & 974 & 34.2 & 109 & 11.1 \\
\hline Average & 1020 & 42.4 & 184 & 17.7 & 1097 & 43.1 & 206 & 17.0 & 1296 & 45.5 & 189 & 14.3 \\
\hline Unclear & 615 & 25.6 & 166 & 28.1 & 635 & 24.9 & 159 & 22.2 & 579 & 20.3 & 146 & 27.7 \\
\hline Frequency of exercise & & & & 0.018 & & & & 0.001 & & & & $<0.001$ \\
\hline None & 1246 & 45.8 & 298 & 24.2 & 1370 & 50.0 & 311 & 21.2 & 1524 & 50.4 & 301 & 20.3 \\
\hline Irregular & 167 & 6.1 & 34 & 19.3 & 138 & 5.0 & 17 & 13.0 & 107 & 3.5 & 20 & 13.4 \\
\hline Regular & 1306 & 48.0 & 247 & 19.1 & 1233 & 45.0 & 196 & 13.8 & 1394 & 46.1 & 170 & 12.6 \\
\hline Comorbidities & & & & $<0.001$ & & & & 0.051 & & & & 0.022 \\
\hline 0 & 879 & 38.5 & 116 & 12.2 & 942 & 33.5 & 153 & 14.2 & 884 & 28.6 & 104 & 12.4 \\
\hline 1 & 690 & 30.2 & 131 & 19.2 & 957 & 34.0 & 185 & 17.6 & 995 & 32.2 & 175 & 16.4 \\
\hline$\geq 2$ & 712 & 31.2 & 187 & 28.5 & 916 & 32.5 & 202 & 19.6 & 1207 & 39.1 & 218 & 18.5 \\
\hline Urinary incontinence & & & & $<0.001$ & & & & 0.002 & & & & $<0.001$ \\
\hline No & 2066 & 76.1 & 384 & 18.8 & 2603 & 90.2 & 485 & 16.5 & 2544 & 79.9 & 367 & 14.0 \\
\hline Yes & 649 & 23.9 & 194 & 29.6 & 284 & 9.8 & 77 & 26.0 & 640 & 20.1 & 156 & 25.5 \\
\hline Depressive symptoms & & & & $<0.001$ & & & & $<0.001$ & & & & $<0.001$ \\
\hline No & 1715 & 71.4 & 282 & 16.3 & 1999 & 76.4 & 297 & 13.6 & 2229 & 79.6 & 282 & 12.5 \\
\hline Yes & 686 & 28.6 & 198 & 30.0 & 617 & 23.6 & 193 & 27.7 & 570 & 20.4 & 139 & 24.9 \\
\hline
\end{tabular}


Table 2 Distribution of falls across selected chronic conditions during the year of survey

\begin{tabular}{|c|c|c|c|c|c|c|c|c|c|c|c|c|}
\hline \multirow[t]{3}{*}{ Characteristics } & \multicolumn{4}{|l|}{2005} & \multicolumn{4}{|l|}{2009} & \multicolumn{4}{|l|}{2013} \\
\hline & \multicolumn{2}{|c|}{$\begin{array}{l}\text { No. of } \\
\text { participants }\end{array}$} & \multicolumn{2}{|c|}{$\begin{array}{l}\text { Prevalence of } \\
\text { falls and } p \text {-value }\end{array}$} & \multicolumn{2}{|c|}{$\begin{array}{l}\text { No. of } \\
\text { participants }\end{array}$} & \multicolumn{2}{|c|}{$\begin{array}{l}\text { Prevalence of } \\
\text { falls and } p \text {-value }\end{array}$} & \multicolumn{2}{|c|}{$\begin{array}{l}\text { No. of } \\
\text { participants }\end{array}$} & \multicolumn{2}{|c|}{$\begin{array}{l}\text { Prevalence of } \\
\text { falls and } p \text {-value }\end{array}$} \\
\hline & $N=2722$ & $\%$ & $n$ & $\%$ & $N=2900$ & $\%$ & $n$ & $\%$ & $N=3200$ & $\%$ & $n$ & $\%$ \\
\hline Hypertension & & & & $<0.001$ & & & & 0.002 & & & & 0.078 \\
\hline No & 1514 & 56.9 & 277 & 17.4 & 1475 & 50.9 & 247 & 14.7 & 1482 & 46.5 & 221 & 14.7 \\
\hline Yes & 1145 & 43.1 & 279 & 25.9 & 1421 & 49.1 & 317 & 20.3 & 1708 & 53.5 & 304 & 17.9 \\
\hline Diabetes & & & & $<0.001$ & & & & 0.032 & & & & 0.131 \\
\hline No & 2181 & 82.2 & 424 & 19.7 & 2337 & 80.7 & 431 & 16.5 & 2471 & 77.5 & 386 & 15.7 \\
\hline Yes & 473 & 17.8 & 134 & 28.4 & 560 & 19.3 & 134 & 21.5 & 717 & 22.5 & 137 & 18.9 \\
\hline Hyperlipidemia & & & & $<0.001$ & & & & 0.979 & & & & 0.014 \\
\hline No & 1847 & 76.7 & 327 & 17.9 & 2159 & 76.0 & 421 & 17.2 & 2290 & 73.2 & 354 & 14.8 \\
\hline Yes & 562 & 23.3 & 149 & 26.6 & 682 & 24.0 & 127 & 17.3 & 839 & 26.8 & 155 & 19.9 \\
\hline Stroke & & & & $<0.001$ & & & & 0.921 & & & & $<0.001$ \\
\hline No & 2493 & 92.4 & 504 & 20.1 & 2687 & 92.8 & 518 & 17.4 & 2918 & 91.3 & 448 & 15.0 \\
\hline Yes & 206 & 7.6 & 67 & 35.5 & 210 & 7.2 & 45 & 17.7 & 277 & 8.7 & 79 & 32.4 \\
\hline Transient ischemic attack & & & & $<0.001$ & & & & 0.037 & & & & 0.008 \\
\hline No & 2447 & 90.3 & 488 & 20.2 & 2702 & 93.7 & 514 & 16.9 & 2838 & 89.6 & 444 & 15.4 \\
\hline Yes & 263 & 9.7 & 89 & 32.5 & 182 & 6.3 & 48 & 24.6 & 329 & 10.4 & 74 & 24.1 \\
\hline Asthma & & & & 0.050 & & & & 0.001 & & & & 0.648 \\
\hline No & 2561 & 94.9 & 533 & 20.9 & 2744 & 94.7 & 519 & 16.9 & 2993 & 93.7 & 496 & 16.6 \\
\hline Yes & 140 & 5.2 & 38 & 29.1 & 155 & 5.3 & 46 & 29.6 & 201 & 6.3 & 30 & 15.0 \\
\hline Kidney disease & & & & $<0.001$ & & & & 0.464 & & & & 0.006 \\
\hline No & 2375 & 91.1 & 467 & 19.5 & 2666 & 92.3 & 501 & 17.2 & 2884 & 90.4 & 456 & 15.5 \\
\hline Yes & 232 & 8.9 & 72 & 33.9 & 223 & 7.7 & 60 & 19.7 & 308 & 9.6 & 70 & 24.3 \\
\hline
\end{tabular}

Note: $p<0.05$ using the chi-square test indicates a statistically significant fall risk across each explanatory variable. The prevalence of falls was estimated by weighing according to sampling probability proportional to the population size

and sex-specific prevalence of falls presented a decrease rate of $2.61 \%$ per year during the period from 2005 to 2013. In contrast to the declining trend of the prevalence rates for falls during the period from 2005 to 2013, an increasing trend was observed for the overall, sexspecific, and age-specific fall-related hospitalization rates between 2003 and 2009 [17]. This trend was especially apparent among older women and individuals aged 7584 years (Fig. 1 ).

The overall and sex-specific and age-specific fallrelated hospitalization rates from 2003 to 2009 were adopted from Bai [17]. Bai's fall-related data were retrieved from the inpatient expenditures by admissions (DD) of the longitudinal national health insurance research database (LHID) 2005. This database contained information on patients aged $\geq 65$ years and hospitalized due to fall injuries with diagnostic code E880-E888 of the International Classification of Disease-Clinical Modification (ninth revision), either for external cause codes or for major diagnosis and secondary diagnosis.

Compared with the univariate logistic regression results (Table 3), Table 4 reveals that independent risk factors of falls identified in the MLR models varied with attenuation of adjusted odds ratios (OR) across these surveys. Risk of falls increased 1.4-1.6 times in women (OR 1.64, 95\% CI 1.26-2.15 in 2005; OR 1.38, 95\% CI 1.09-1.76 in 2009), but not with age. Those risk factors that were independently associated with a higher risk of falls included urinary incontinence (OR 1.42, 95\% CI 1.04-1.94 in 2013), depressive symptoms (OR 1.51, 95\% CI 1.12-2.03 in 2005; OR 1.77, 95\% CI 1.35-2.31 in 2009; OR 1.45, 95\% CI 1.06-1.98 in 2013), and having difficulty in performing one ADL (OR 2.39, 95\% CI 1.25-4.58 in 2005; OR 2.74, 95\% CI 1.55-4.86 in 2013), having difficulty in performing two or more IADLs (OR 1.45 , 95\% CI 1.00-2.11 in 2005), and unclear vision (OR 1.92, 95\% CI 1.36-2.72 in 2013), instead of using sleeping pills. Moreover, a fall-risk gradient was found between having one (OR 1.61, 95\% CI 1.16-2.24) and two or more comorbidities (OR 2.41, 95\% CI 1.74-3.35) in 2005. Notably, both regular and irregular exercises were not associated with a protective effect from falls.

Fig. 2 demonstrates that the effect size varied by age and sex of study population and outcome indicators 
Table 3 Univariate logistic regression analyses for falls by the year of survey

\begin{tabular}{|c|c|c|c|}
\hline \multirow[t]{2}{*}{ Covariate (reference) } & 2005 & 2009 & 2013 \\
\hline & OR 95\% Cl & OR 95\% Cl & OR 95\% Cl \\
\hline \multicolumn{4}{|l|}{ Age (65-69) } \\
\hline $70-74$ & $1.30(0.99-1.71)$ & $1.40(1.06-1.84)$ & $1.40(1.04-1.89)$ \\
\hline $75-79$ & $1.48(1.12-1.96)$ & $1.20(0.90-1.62)$ & $1.58(1.15-2.17)$ \\
\hline $80-84$ & $1.92(1.39-2.65)$ & $1.83(1.34-2.51)$ & $1.67(1.20-2.34)$ \\
\hline $85+$ & $1.74(1.14-2.65)$ & $1.66(1.13-2.42)$ & $2.33(1.62-3.35)$ \\
\hline \multicolumn{4}{|l|}{ Sex (male) } \\
\hline Female & $1.80(1.47-2.21)$ & $1.57(1.28-1.93)$ & $1.18(0.95-1.45)$ \\
\hline \multicolumn{4}{|l|}{ ADL difficulty (none) } \\
\hline 1 task & $3.84(2.34-6.30)$ & $2.29(1.46-3.60)$ & $5.00(3.22-7.75)$ \\
\hline$\geqq 2$ tasks & $2.93(2.23-3.85)$ & $2.22(1.71-2.87)$ & $2.33(1.77-3.07)$ \\
\hline \multicolumn{4}{|l|}{ IADL difficulty (none) } \\
\hline 1 task & $1.32(0.96-1.82)$ & $1.92(1.18-3.11)$ & $1.42(1.00-2.01)$ \\
\hline$\geqq 2$ tasks & $3.14(2.52-3.90)$ & $2.36(1.85-3.00)$ & $2.82(2.24-3.54)$ \\
\hline \multicolumn{4}{|l|}{ Use of sleeping pills (no) } \\
\hline Yes & $1.56(1.17-2.08)$ & $1.48(1.11-1.96)$ & $1.58(1.22-2.04)$ \\
\hline \multicolumn{4}{|l|}{ Vision (clear) } \\
\hline Average & $1.02(0.78-1.33)$ & $1.39(1.07-1.82)$ & $1.33(1.01-1.75)$ \\
\hline Unclear & $1.86(1.41-2.45)$ & $1.94(1.44-2.60)$ & $3.07(2.28-4.13)$ \\
\hline \multicolumn{4}{|l|}{ Comorbidities (0) } \\
\hline 1 & $1.71(1.27-2.30)$ & $1.30(1.00-1.68)$ & $1.39(1.03-1.86)$ \\
\hline$\geqq 2$ & $2.86(2.15-3.79)$ & $1.47(1.14-1.91)$ & $1.60(1.21-2.11)$ \\
\hline \multicolumn{4}{|l|}{ Urinary incontinence (no) } \\
\hline Yes & $1.82(1.46-2.26)$ & $1.78(1.33-2.38)$ & $2.10(1.67-2.65)$ \\
\hline \multicolumn{4}{|c|}{ Depressive symptoms (no) } \\
\hline Yes & $2.20(1.76-2.75)$ & $2.44(1.94-3.07)$ & $2.32(1.80-3.00)$ \\
\hline \multicolumn{4}{|c|}{ Frequency of exercise (none) } \\
\hline Irregular & $0.75(0.48-1.17)$ & $0.56(0.34-0.91)$ & $0.60(0.33-1.10)$ \\
\hline Regular & $0.74(0.60-0.91)$ & $0.60(0.48-0.74)$ & $0.57(0.45-0.71)$ \\
\hline
\end{tabular}

selected. During 2005 and 2009, the effect size of prevalence of falls presented as $14.5 \%$ for old men and $21.4 \%$ for old women, and 17.2, 11.5, 29.3, 18.1, and $18.4 \%$ respectively for those aged $65-69,70-74,75-79,80-84$, and $\geq 85$ years. In contrast to the universal positive effect on the prevalence of falls among older adults, the effect size of fall-related hospitalization rates revealed a $2 \%$ relative risk reduction only for those aged 65-74 years, but deteriorated for those aged 75-84 (-10.9\%), for old men $(-2.0 \%)$ and old women $(-10.7 \%)$.

\section{Discussion}

Our study is the first to present the differential effect of fall prevention programs on falls and fall-related hospitalizations. Several significant independent risk factors for falls identified included the following: female sex, difficulty in performing one basic ADL, difficulty in performing two or more instrumental ADLs, unclear vision, comorbidities, urinary incontinence, and depressive symptoms. However, no significant risk of falling was associated with advanced age, use of sleeping pills, and performing regular or irregular exercise. Furthermore, these risk factors and differential prevention effect may help dictate the future direction of fall prevention policies.

Variation of the time-dependent characteristics of the participants by survey reflected more the influence of demographic, epidemiological, and health transitions [19], rather than cross-survey comparability. The increased prevalence of multiple comorbidities may result from a rapidly aging population, earlier detection, and better treatment of disease [20]. Our analyses on the effect sizes indicate that the effect of fall prevention 


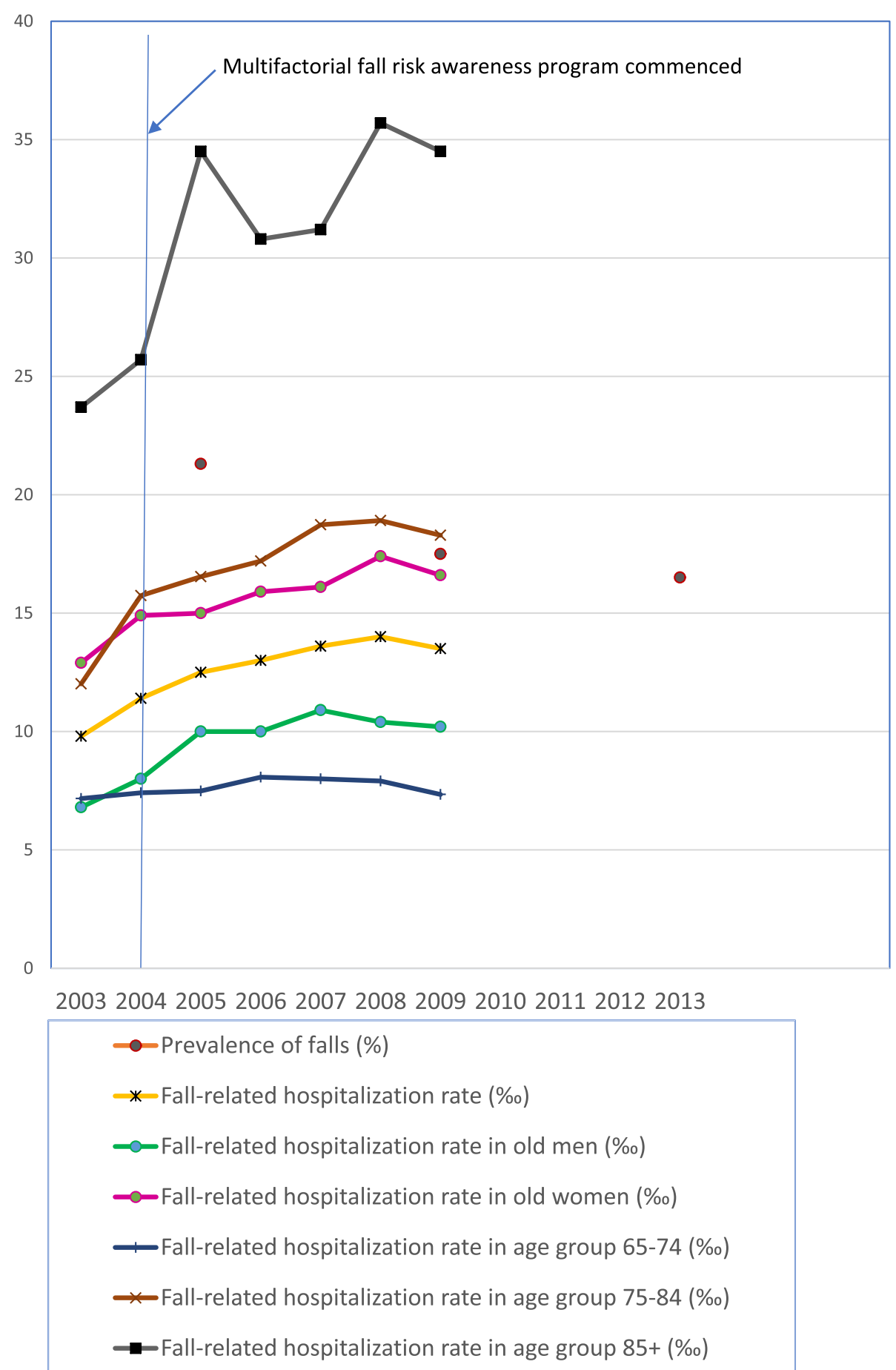

Fig. 1 Time trends in the prevalence of falls and fall-related hospitalization rates

programs varied by age and sex of study population and outcome indicators selected. Successful fall prevention strategies are supposed to encompass the full array of contributing variables or causes over a broad target audience with user-designed strategies [21] and to accomplish a significant risk reduction in falls and fall- related hospitalizations. On one hand, the declining prevalence of falls may reflect the combined effect of these community-based multifactorial fall risk awareness programs mentioned above. On the other hand, despite appearing to serve the wider community-dwelling older people, these programs may benefit the young-old (65 
Table 4 Multivariate logistic regression analyses for falls by the year of survey

\begin{tabular}{|c|c|c|c|c|c|c|}
\hline \multirow{2}{*}{$\begin{array}{l}\text { Covariate (reference) } \\
\text { Age (65-69) }\end{array}$} & \multicolumn{2}{|l|}{2005} & \multicolumn{2}{|l|}{2009} & \multicolumn{2}{|l|}{2013} \\
\hline & & & & & & \\
\hline $70-74$ & 1.16 & $(0.83-1.62)$ & 1.26 & $(0.93-1.69)$ & 1.13 & $(0.81-1.58)$ \\
\hline $75-79$ & 1.24 & $(0.87-1.76)$ & 0.87 & $(0.62-1.22)$ & 1.17 & $(0.81-1.70)$ \\
\hline $80+$ & 1.34 & $(0.88-2.03)$ & 1.35 & $(0.97-1.89)$ & 1.19 & $(0.82-1.73)$ \\
\hline \multicolumn{7}{|l|}{ Sex (male) } \\
\hline Female & 1.64 & $(1.26-2.15)$ & 1.38 & $(1.09-1.76)$ & 0.93 & $(0.72-1.20)$ \\
\hline \multicolumn{7}{|l|}{ ADL difficulty (none) } \\
\hline 1 task & 2.39 & $(1.25-4.58)$ & 0.44 & $(0.10-1.87)$ & 2.74 & $(1.55-4.86)$ \\
\hline$\geq 2$ tasks & 1.41 & $(0.80-2.47)$ & 0.42 & $(0.09-2.04)$ & 1.14 & $(0.66-1.95)$ \\
\hline \multicolumn{7}{|l|}{ IADL difficulty (none) } \\
\hline 1 task & 0.76 & $(0.51-1.14)$ & 1.41 & $(0.74-2.72)$ & 1.13 & $(0.77-1.66)$ \\
\hline$\geq 2$ tasks & 1.45 & $(1.00-2.11)$ & 4.56 & $(0.98-21.23)$ & 1.27 & $(0.85-1.90)$ \\
\hline \multicolumn{7}{|l|}{ Use of sleeping pills (no) } \\
\hline Yes & 1.09 & $(0.75-1.60)$ & 1.06 & $(0.75-1.49)$ & 1.21 & $(0.88-1.67)$ \\
\hline \multicolumn{7}{|l|}{ Vision (clear) } \\
\hline Average & 0.93 & $(0.69-1.27)$ & 1.25 & $(0.94-1.65)$ & 1.10 & $(0.82-1.48)$ \\
\hline Unclear & 1.09 & $(0.77-1.55)$ & 1.23 & $(0.88-1.71)$ & 1.92 & $(1.36-2.72)$ \\
\hline \multicolumn{7}{|l|}{ Comorbidities (0) } \\
\hline 1 & 1.61 & $(1.16-2.24)$ & 1.16 & $(0.87-1.54)$ & 1.18 & $(0.85-1.64)$ \\
\hline$\geq 2$ & 2.41 & $(1.74-3.35)$ & 1.19 & $(0.89-1.61)$ & 1.12 & $(0.81-1.54)$ \\
\hline \multicolumn{7}{|l|}{ Urinary incontinence (no) } \\
\hline Yes & 1.09 & $(0.80-1.49)$ & 1.29 & $(0.90-1.84)$ & 1.42 & $(1.04-1.94)$ \\
\hline \multicolumn{7}{|c|}{ Depressive symptoms (no) } \\
\hline Yes & 1.51 & $(1.12-2.03)$ & 1.77 & $(1.35-2.31)$ & 1.45 & $(1.06-1.98)$ \\
\hline \multicolumn{7}{|c|}{ Frequency of exercise (none) } \\
\hline Irregular & 1.20 & $(0.70-2.04)$ & 0.77 & $(0.46-1.29)$ & 0.87 & $(0.45-1.69)$ \\
\hline Regular & 1.12 & $(0.85-1.49)$ & 0.81 & $(0.63-1.04)$ & 0.80 & $(0.62-1.03)$ \\
\hline
\end{tabular}

Note: Adjusted odds ratios and $95 \%$ confidence interval (OR and $95 \% \mathrm{Cl}$ ) are presented for each dummy variable. Variables controlled across three waves of survey in the MLR model included age, sex, developing difficulty in performing ADLs or IADLs, use of sleeping pills, vision, comorbidities, urinary incontinence, depressive symptoms, and frequency of exercise

years old) over the old-old ( $\geq 75$ years) population for prevention from fall-related hospitalizations. The differential effect of these programs can be attributed to the differences in study population and factors influencing implementation. Compared with the community-based prevalence of falls, the fall-related hospitalization rates were estimated on a broader population base including those older people living in long-term institutionalized care. In spite of a small share of the national elderly, these institutionalized older people, who have twice the incidence rate of major injuries of their home-dwelling counterparts [22], were not exposed to these programs. More importantly, four factors which influence implementation of fall prevention programs can be noted, including restricted access [23], prevalence of disability [24], adapting for community, and transforming identities
[25]. First, the old-old adults may be more likely to have restricted access to preventive services due to social determinants of health inequality [23], such as financial or geographic barriers and digital divide. Second, as the population is rapidly aging, the functional disability status among older Taiwanese accelerates over time, especially among women and the old-old population. Older women suffer from disproportionately greater levels of disability [24] and are more susceptible to falls and fall-related injuries than their male counterparts (Fig. 1). Third, social and cultural influences are also crucial for individual choice about participation in fall prevention programs [25], such as learning use of assistive devices and uptake of exercise interventions. Fourth, older adults may override risk-averse advice due to their pride and fear of loss of identity of independence and self-esteem [25]. 


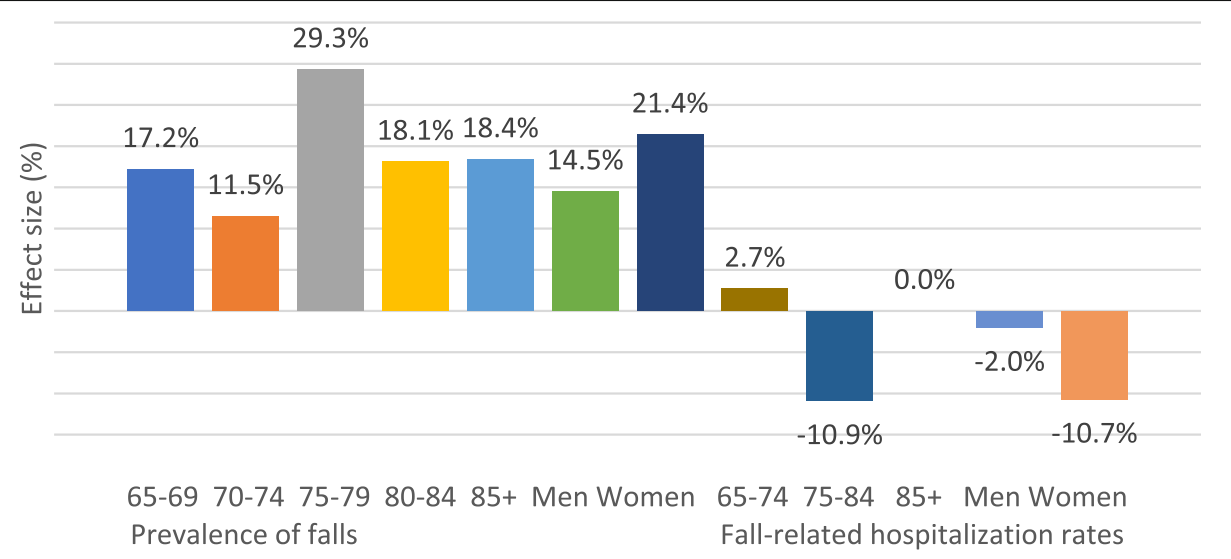

Fig. 2 Effect sizes of prevalence of falls and fall-related hospitalization rates during 2005 and 2009

As regards the sociodemographic risk factors for falls that were identified using the MLR models, women had a higher risk of falls than men. Two possible explanations may be applied: (1) they are more liable to osteoporosis and reduced knee muscle strength [26] and (2) they are more susceptible to an indoor fall [27]. The association between difficulties in performing two or more IADLs and an increased risk of falls is compatible with the findings of previous reports [28]. However, there was no corresponding finding among those older adults with difficulty in performing ADLs. A possible explanation is that they were subjected to selective survival [29] and the sample number became too small to obtain a stable OR across the three waves of survey. Another explanation is that those older adults who had difficulty in performing ADLs might be restricted from activity at risk of falls because of existing multiple health problems [30].

Considering biological factors, our finding that older adults with unclear vision had an OR that was twice as high as older adults with clear vision aligns with that in a previous report by Lord [31]. Our finding that having any of the selected chronic conditions was associated with a higher risk of falls is compatible with previous falls and multi-morbidity studies in terms of asthma [32], hypertension [33], diabetes [34], stroke or transient ischemic attack [35, 36], and chronic kidney disease $[37,38]$. Moreover, our finding in the fall-risk gradient among older people having one or two or more comorbidities is not only consistent with those of past research $[39,40]$, but also strengthens the assertion of the additive effect of chronic disease on fall risk [33].

Besides, the $40 \%$ higher risk of falls among respondents with urinary incontinence in the 2013 survey was compatible with the conclusions drawn from a previous systematic review [41]. The fact that depressive symptoms were proven to be a significant risk factor of falls might be explained by an intricate bidirectional and self-perpetuating interaction between depression and falls [42].
The main strength of our study is that it has a comparable fall-related questionnaire administered to a large sample size of older adults on a national scale. These factors make it possible to identify the prevalence and risk factors of falls across the three waves of surveys. The national survey data and data of fall-related hospitalizations [17] complemented each other to open up a window of opportunity for us to examine the differential effect of fall prevention programs. However, several limitations of this study are worthy of mention. First, a crosssectional survey cannot infer a causal relationship between the outcome and explanatory variables. Second, data collection through questionnaire interview might be subject to recall bias, and result in underreporting of falls and non-identification of multiple falls. Additionally, the fall risk among those aged 80 and over, which has shown an increasing time trend in China [39], might be biased with a limited sample size in the survey data. Besides, some older adults were reluctant to verbalize their incontinence because of embarrassment or because of its interference with sexual function. Third, the effect sizes were estimated during too short an observation period, from 2005 to 2009, to indicate long-term variation of fall-related hospitalization rates. Fourth, the association between fall prevention programs and prevention effect could be confounded by other overlapping health promotion programs, such as Community Health Building and Safe Communities [14]. Accordingly, further assessment of risk factor studies on falls have to be conducted with either fall diaries or weekly or monthly follow-up to identify multiple or recurrent falls and minimize reliance on recall of fall events $[18,43]$. It is also worthy to conduct further studies to evaluate fall prevention programs in terms of efficiency, effectiveness, and economy [44].

Our study findings imply that a combination of lowrisk and high-risk strategies [45] should be adopted to tailor fall prevention programs to people with several different risk factors for falls. Current fall prevention 
guidelines [46] do not address the potential risk of falls derived from multi-morbidity [32,33]. Thus, an approach that accounts for adults who have multimorbidity and are prescribed multiple medicines is recommended because such population has a higher risk for adverse events and drug interactions [47]. Considering the projected 2.7-fold growth in the number of hip fractures between 2010 and 2035 [48], the fall epidemic must be surveyed regularly, as the identification of risk factors and differential prevention effect in older people may help with developing individualized fall risk assessments [43] among high-risk seniors.

\section{Conclusions}

This study gives an illustration of using national survey data in conjunction with data of fall-related hospitalizations to investigate the effect of fall prevention programs, in addition to examining the prevalence and risk factors of falls among community-dwelling Taiwanese older people. Although the decline in fall prevalence over time supports existing fall intervention strategies in Taiwan, the differential prevention effect and identification of risk factors in older people suggest the necessity of adjusting fall prevention programs.

\section{Supplementary Information}

The online version contains supplementary material available at https://doi. org/10.1186/s12877-020-01922-z.

Additional file 1: Table S1. Definitions of explanatory variables.

Additional file 2: Table S2. Multiple linear regression model for the age- and sex-specific prevalence of falls.

\section{Abbreviations}

ADL: Activities of daily living; IADL: Instrumental activities of daily living; MLR: Multivariable logistic regression; NHIS: National Health Interview Survey; Es: Effect size of relative risk reduction; HPA: Health Promotion Administration

\section{Acknowledgments}

The authors are indebted to Researcher Long-Sheng Chen, Health Promotion Administration, who provided a critical review of an earlier draft of this manuscript.

\section{Authors' contributions \\ YJT and PYY had full access to all NHIS data and take responsibility for the integrity of the data and the accuracy of the data analysis. YJT was responsible for conceptualization and design of the study. PYY was responsible for the data curation and formal analysis. YJT drafted the manuscript and was responsible for interpretation of the data. YCY and MRL helped with the study methodology and participated in interpretation of the data and revision of the manuscript. YWW helped with funding acquisition, resource allocation, supervision, and writing review and editing of the manuscript. All authors contributed to the critical revision of the manuscript for important intellectual content, and all approved the article submitted for publication.}

\section{Funding}

Although the data collection of NHIS was supported by the Health Promotion Administration, the research team was independent in the design of study, analysis, and interpretation of data and in writing the manuscript based on the research program.

\section{Availability of data and materials}

The NHIS datasets used and/or analyzed during the current study were available from the Health and Welfare Data Science Center, Ministry of Health and Welfare, Taiwan, upon regular application.

\section{Ethics approval and consent to participate}

Administrative permission to use the NHIS data was not obtained until the research program "Prevalence and risk factors of falls among communitydwelling elderly in Taiwan" was approved (MOHW 107-HPA-H-315-000725). Data used in our study was de-identified before its use. The NHIS was approved by the Institutional Review Board of the National Health Research Institute (HPA09808001092; EC1020502).

\section{Consent for publication}

Not applicable.

\section{Competing interests}

The authors declare that they have no competing interests.

\section{Author details}

${ }^{1}$ Health Promotion Administration, Ministry of Health and Welfare, Taipei, Taiwan. ${ }^{2}$ Department of Geriatrics and Gerontology, College of Medicine, National Cheng-Kung University and Hospital, Tainan, Taiwan. ${ }^{3}$ Graduate Institute of Injury Prevention and Control, College of Public Health, Taipei Medical University, Taipei, Taiwan. ${ }^{4}$ Hualien Tzu Chi Hospital, Tzu Chi

University and Hospital, Hualien, Taiwan.

Received: 22 January 2020 Accepted: 22 November 2020

Published online: 09 December 2020

\section{References}

1. World Health Organization. WHO Global Report on Falls Prevention in Older Age: World Health Organization; 2007. https://extranet.who.int/ agefriendlyworld/wp-content/uploads/2014/06/WHo-Global-report-on-fallsprevention-in-older-age.pdf. Accessed 25 Jan 2019.

2. Haagsma JA, Graetz N, Bolliger I, Naghavi M, Higashi H, Mullany EC, et al. The global burden of injury: incidence, mortality, disability-adjusted life years and time trends from the global burden of disease study 2013. Inj Prev. 2016:22:3-18.

3. Florence CS, Bergen G, Atherly A, Burns E, Stevens J, Drake C. Medical costs of fatal and nonfatal falls in older adults. J Am Geriatr Soc. 2018;66:693-8.

4. Houry D, Florence C, Baldwin G, Stevens J, McClure R. The CDC injury Center's response to the growing public health problem of falls among older adults. Am J Lifestyle Med. 2016;10:74-7.

5. Scuffham P, Chaplin S, Legood R. Incidence and costs of unintentional falls in older people in the United Kingdom. J Epidemiol Community Health. 2003;57:740-4.

6. Watson W, Clapperton A, Mitchell R. The burden of fall-related injury among older persons in New South Wales. Aust NZ J Public Health. 2011;35:170-5.

7. Deandrea S, Lucenteforte E, Bravi F, Foschi R, La Vecchia C, Negri E. Risk factors for falls in community-dwelling older people: a systematic review and meta-analysis. Epidemiology. 2010;21:658-68. http://www.jstor.org/ stable/20788204. Accessed 6 April 2020

8. Timsina LR, Willetts $J$, Brennan MJ, Marucci-Wellman H, Lombardi DA, Courtney TK, et al. Circumstances of fall-related injuries by age and gender among community-dwelling adults in the United States. PLoS One. 2017;12: e0176561.

9. Gale CR, Cooper C, Sayer AA. Prevalence and risk factors for falls in older men and women: The English Longitudinal Study of Ageing. Age Ageing. 2016:45:789-94

10. Williams JS, Kowal $\mathrm{P}$, Hestekin $\mathrm{H}, \mathrm{O}^{\prime}$ Driscoll $\mathrm{T}$, Peltzer $\mathrm{K}$, Yawson $\mathrm{A}$, et al. Prevalence, risk factors and disability associated with fall-related injury in older adults in low- and middle-income countries: results from the WHO study on global AGEing and adult health (SAGE). BMC Med. 2015:13:147.

11. Pengpid S, Peltzer K. Prevalence and risk factors associated with injurious falls among community-dwelling older adults in Indonesia. Curr Gerontol Geriatr Res. 2018;2018:5964305. Published 3 Jun 2018. https://doi.org/10. $1155 / 2018 / 5964305$

12. Rau CS, Lin TS, Wu SC, Yang JC, Hsu SY, Cho TY, et al. Geriatric hospitalizations in fall-related injuries. Scand J Trauma Resusc Emerg Med. 2014;22:63. 
13. Hsu HC, Jhan LJ. Risk factors of falling among the elderly in Taiwan: a longitudinal study. Taiwan Geriatr Gerontol. 2008;3:141-54.

14. Health Promotion Administration. 2018 Annual Report Health Promotion Administration. Taipei: Health Promotion Administration, Ministry of Health and Welfare, R.O.C. (Taiwan); 2019.

15. Weng WS, Liu CY, Chen YJ, Liu JS, Chang HY, Liang KY, et al. Sampling design for the 2005 National Health Interview Survey. The 2005 National Health Interview Survey Research Brief, vol. 2. Taipei: NHRI \& BHP; 2007. [in Chinese] https://www.hpa.gov.tw/Pages/Detail.aspx?nodeid=234\&pid=1278.

16. Andresen EM, Malmgren JA, Carter WB, Patrick DL. Screening for depression in well older adults: evaluation of a short form of the CES-D. Am J Prev Med. 1994;10:77-84.

17. Bai CH. Projection of medical expenditure due to fall injuries among older adults in Taiwan. Taichung: Bureau of Health Promotion; 2012. (Commission research project to Taipei Medical University) [in Chinese].

18. Lord SR, Sherrington C, Menz HB. Falls in older people: Risk factors and strategies for prevention. Cambridge: Cambridge University Press; 2001.

19. Kuate Defo B. Demographic, epidemiological, and health transitions: are they relevant to population health patterns in Africa? Glob Health Action. 2014;7:22443. Published 2014 May 15. https://doi.org/10.3402/ gha.v7.22443.

20. Fu S, Huang N, Chou YJ. Trends in the prevalence of multiple chronic conditions in Taiwan from 2000 to 2010: a population-based study. Prev Chronic Dis. 2014;11:E187. Published 2014 Oct 23. https://doi.org/10.5888/ pcd11.140205

21. Vaziri DD, Aal K, Ogonowski C, Von Rekowski T, Kroll M, Marston HR, et al. Exploring user experience and technology acceptance for a fall prevention system: results from a randomized clinical trial and a living lab. Eur Rev Aging Phys Act. 2016;13:6. Published 2016 Jun 10. https://doi.org/10.1186/ s11556-016-0165-z

22. Luukinen $H$, Koski $K$, Honkanen R. Incidence of injury-causing falls among older adults by place of residence: a population-based study. J Am Geriatr Soc. 1995;43:871-6.

23. Chiou ST, Marmot M. Health inequalities in Taiwan. Co-published by Taiwan Health Promotion Administration, Department of Health and Welfare, and UCL Institute of Health Equity. Taipei: Government Online Bookstore (http:// www.govbooks.com.tw); 2016. www.instituteofhealthequity.org. Accessed 12 Aug 2020.

24. Liang J, Wang CN, Xu X, Hsu HC, Lin HS, Lin YH. Trajectory of functional status among older Taiwanese: gender and age variations. Soc Sci Med. 2010;71:1208-17.

25. Child S, Goodwin V, Garside R, Jones-Hughes T, Boddy K, Stein K. Factors influencing the implementation of fall-prevention programmes: a systematic review and synthesis of qualitative studies. Implement Sci. 2012;7:91. Published 2012 Sep 14. doi:https://doi.org/10.1186/1748-5908-7-91.

26. Murray MP, Duthie EH Jr, Gambert SR, Sepic SB, Mollinger LA. Age-related differences in knee muscle strength in normal women. J Gerontol. 1985;40: 275-80.

27. Kelsey JL, Berry SD, Procter-Gray E, et al. Indoor and outdoor falls in older adults are different: the MOBILIE Boston study. J Am Geriatr Soc. 2010;58: 2135-41.

28. Nourhashémi F, Andrieu S, Gillette-Guyonnet S, Vellas B, Albarède JL, Grandjean $\mathrm{H}$. Instrumental activities of daily living as a potential marker of frailty: a study of 7364 community-dwelling elderly women (the EPIDOS study). J Gerontol A Biol Sci Med Sci. 2001;56:M448-53.

29. Stineman MG, Xie D, Pan Q, Kurichi JE, Zhang Z, Saliba D, et al. All-cause 1-, 5-, and 10-year mortality in elderly people according to activities of daily living stage. J Am Geriatr Soc. 2012;60:485-92. https://doi.org/10.1111/j. 1532-5415.2011.03867x

30. Bath PA, Morgan K. Differential risk factor profiles for indoor and outdoor falls in older people living at home in Nottingham, UK. Eur J Epidemiol. 1999;15:65-73

31. Lord SR. Visual risk factors for falls in older people. Age Ageing. 2006; 35(Suppl 2):ii42-5. https://doi.org/10.1093/ageing/afl085.

32. Paliwal Y, Slattum PW, Ratliff SM. Chronic health conditions as a risk factor for falls among the community-dwelling US older adults: a zero-inflated regression modeling approach. Biomed Res Int. 2017;2017:5146378. https:// doi.org/10.1155/2017/5146378.

33. Sibley KM, Voth J, Munce SE, Straus SE, Jaglal SB. Chronic disease and falls in community-dwelling Canadians over 65 years old: a populationbased study exploring associations with number and pattern of chronic conditions. BMC Geriatr. 2014 Feb 14;14:22. https://doi.org/10.1186/1471 2318-14-22.

34. Yang Y, Hu X, Zhang Q, Zou R. Diabetes mellitus and risk of falls in older adults: a systematic review and meta-analysis. Age Ageing. 2016;45:761-7 Epub 2016 Aug 11.

35. Dolinis J, Harrison JE, Andrews GR. Factors associated with falling in older Adelaide residents. Aust N Z J Public Health. 1997;21:462-8. https://doi.org/ 10.1111/j.1467-842x.1997.tb01736.x.

36. Mackintosh SF, Goldie P, Hill K. Falls incidence and factors associated with falling in older, community-dwelling, chronic stroke survivors ( $>1$ year after stroke) and matched controls. Aging Clin Exp Res. 2005;17:74-81. https:// doi.org/10.1007/BF03324577.

37. Papakonstantinopoulou K, Sofianos I. Risk of falls in chronic kidney disease. J Frailty Sarcopenia Falls. 2017;2:33-8. https://doi.org/10.22540/JFSF-02-033.

38. López-Soto PJ, De Giorgi A, Senno E, et al. Renal disease and accidental falls: a review of published evidence. BMC Nephrol. 2015;16:176. Published 2015 Oct 29. https://doi.org/10.1186/s12882-015-0173-7.

39. Wu H, Peng O. Fall prevalence, time trend and its related risk factors among elderly people in China. Arch Gerontol Geriatr. 2017;73:294-9. https://doi. org/10.1016/j.archger.2017.08.009.

40. Qin Z, Baccaglini L. Distribution, determinants, and prevention of falls among the elderly in the 2011-2012 California health interview survey. Public Health Rep. 2016;131:331-9.

41. Chiarelli PE, Mackenzie LA, Osmotherly PG. Urinary incontinence is associated with an increase in falls: a systematic review. Aust J Physiother. 2008:55:89-95.

42. Iaboni A, Flint AJ. The complex interplay of depression and falls in older adults: a clinical review. Am J Geriatr Psychiatry. 2013;21:484-92.

43. National Institute for Health and Care Excellence. Falls. Assessment and prevention of falls in older people. 2013. (NICE guidance number guidance. nice.org.uk/CG161). http: //www.nice.org.uk/guidance/CG161. Accessed 4 July 2020.

44. Naidoo J, Wills J. Evaluation in health promotion. In: Health promotionFoundation for Practice. 1st ed. London: Baillière Tindall; 1998. p. 279-95.

45. Rose G. The strategy of preventive medicine. New York: Oxford University Press; 1992.

46. Panel on Prevention of Falls in Older Persons, American Geriatrics Society and British Geriatrics Society. Summary of the Updated American Geriatrics Society/British Geriatrics Society clinical practice guideline for prevention of falls in older persons. J Am Geriatr Soc. 2011;59:148-57. https://doi.org/10. 1111/j.1532-5415.2010.03234.x.

47. National Guideline Center. Multimorbidity: clinical assessment and management Multimorbidity: assessment, prioritisation and management of care for people with commonly occurring multimorbidity. NICE guideline NG56, 2016. (Commissioned by the National Institute for Health and Care Excellence).

48. Chen IJ, Chiang CY, Li YH. Nationwide cohort study of hip fractures: trends in the incidence rates and projections up to 2035. Osteoporos Int. 2015;26: $681-8$.

\section{Publisher's Note}

Springer Nature remains neutral with regard to jurisdictional claims in published maps and institutional affiliations.

Ready to submit your research? Choose BMC and benefit from:

- fast, convenient online submission

- thorough peer review by experienced researchers in your field

- rapid publication on acceptance

- support for research data, including large and complex data types

- gold Open Access which fosters wider collaboration and increased citations

- maximum visibility for your research: over $100 \mathrm{M}$ website views per year

At $\mathrm{BMC}$, research is always in progress.

Learn more biomedcentral.com/submission 